\title{
A pesquisa dialógica como ato lúdico de conhecer
}

Marcos Paulo de Passos

Doutorando em Ciência da Informação. Mestre em Ciência da Informação, pela Escola de Comunicações e Artes da Universidade de São Paulo. Integrante e pesquisador do Colaboratório de Infoeducação (COLABORI) da ECA-USP

Ivete Pieruccini

Docente e pesquisadora da Escola de
Comunicações e Artes, da Universidade de São
Paulo.Mestre e doutora em Ciências da
Comunicação, pela ECA/USP. Coordenadora
acadêmica do Colaboratório de Infoeducação
(COLABORI) da ECA-USP

http://dx.doi.org/10.1590/1981-5344/2652

O estudo permitiu identificar questões essenciais ligadas aos processos inerentes ao ato de conhecer, especialmente, ligados às aprendizagens informacionais, na perspectiva das relações entre dispositivos e apropriação da informação. Abordamos os conceitos de pesquisa escolar, reconhecida prática pedagógica que confere aos alunos participação ativa nos processos de ensino-aprendizagem em contextos educacionais formais e não formais e, de lúdico, tomado como conceitooperatório para análise de dinâmicas e processos de pesquisa realizados por jovens em dispositivo informacional dialógico - a Estação do Conhecimento Einstein, em Paraisópolis, São Paulo. Trata-se de pesquisa exploratória, de natureza qualitativa, do tipo etnográfica. Inscreve-se no campo da Infoeducação e, sob a assertiva do protagonismo cultural - sujeito que mantém atitudes afirmativas, críticas e criativas com os signos -, concluímos que a pesquisa dialógica, caracterizada como prática negociada e espontaneamente realizada por crianças e jovens no quadro da Estação do Conhecimento, apresenta aspectos que podem caracterizar uma nova abordagem dessa prática, não somente como forma de estimular grupos em seus processos escolares, mas de favorecimento para a construção do valor e de vínculos com o ato de conhecer, com o conhecimento, com a cultura. A prática da pesquisa, como ato lúdico de 
conhecer, mostrou-se categoria essencial à apropriação cultural.

Palavras-chave: Pesquisa escolar; Lúdico; Dispositivo informacional dialógico; Ordem informacional dialógica; Infoeducação.

\section{The dialogic research as playful act of knowing}

By means of this study, essential issues related to the processes iherent in the act of knowing, especially, that are conected to the informational learning, in the view of the relationship between devices and appropriation of information. The concepts of scholarly research were approched, a recognized pedagogical practice that provides students with active participation in the teaching-learning processes in formal and non-formal educational settings and, playful, taken as a conceptoperatively to the dynamic analysis and research processes conducted by young people in dialogic informational device - the (knowledge station) Estação do Conhecimento Einstein in Paraisópolis, São Paulo. It is an exploratory, qualitative and ethnographic type. This work takes place inside of the field of Infoeducation, under the assertion of the cultural leadership - a subject that keeps affirmative, critical and creative attitudes with the signs-, and has showed that the dialogic research, characterized as negotiated practice and spontaneously performed by children and teenagers as part of the Estação do Conhecimento, presents aspects that can characterize a new approach of this practice, not only as a way to encourage groups in their school processes, but also to stimulate young people to build value and to realize the links with the act of knowing, with knowledge, with the culture. The practice of research, as playful act of knowing, proved essential category of cultural appropriation.

Keywords: Scholarly research; Playful; Dialogic informational device; Dialogic informational order; Infoeducation.

Recebido em 08.12.2015 Aceito em 13.06.2016 


\section{Introdução}

Este trabalho apresenta resultados de pesquisa realizada em nível de mestrado no campo da Ciência da Informação, tratando das relações entre dispositivos informacionais, tais como bibliotecas, e processos de apropriação de conhecimento e cultura.

O problema em foco nesse estudo nasceu da observação dos modos de relação entre adolescentes e jovens com uma Biblioteca Pública, alocada em um Centro Educacional Unificado (CEU) ${ }^{1}$ da cidade de São Paulo. A partir de práticas profissionais como bibliotecário da instituição, observamos que tais públicos buscavam a biblioteca para participar de atividades de entretenimento, em especial, oficinas presenciais com o jogo de xadrez (PASSOS, 2011), propostas como um programa regular, tendo em vista o oferecimento de alternativas para a ocupação daquele dispositivo cultural e educativo. $O$ interesse pela frequência ao espaço, de modo sistemático, era exclusivamente voltado à referida prática e as possibilidades e recursos existentes, tais como a consulta, leitura ou empréstimo de livros, multimídias e outros formatos; ou mesmo os serviços de orientação à pesquisa escolar ou o acesso à rede www (world wide web) oferecidos de modo reiterado, não mobilizavam o interesse dos participantes desses grupos, apesar de estudantes.

Paralelamente, o contato com outra experiência em espaço de informação e cultura - a Estação do Conhecimento Einstein-Paraisópolis -, em contexto sociocultural semelhante ao da biblioteca do CEU, mostravase bastante diferente. Ali, grupos de crianças, adolescentes e jovens em contraturno escolar, não apenas frequentavam 0 espaço, mas participavam de modo afirmativo em programa destinado às aprendizagens de pesquisa, independentemente de demandas escolares. A observação das diferenças entre as duas situações chamava a atenção, mostrando, porém, semelhanças em relação ao genuíno interesse dos grupos pelas respectivas práticas.

A partir de tal constatação, nosso foco voltou-se à identificação e compreensão das questões que propiciavam tal quadro favorável de relações do grupo da Estação do Conhecimento (EC) com os repertórios ali existentes, inspirados pela compreensão da força exercida pelas práticas lúdicas sobre o interesse dos participantes do Programa de Xadrez na Biblioteca do CEU.

O objetivo de nosso estudo, assim, era indagar sobre tal questão nos processos de construção de conhecimento, especialmente, nas dinâmicas implicadas na pesquisa realizada pelas crianças e jovens da

\footnotetext{
${ }^{1}$ Centro Educacional Unificado (CEU) é um equipamento público, situado nas zonas de periferias da cidade e está composto por Escolas de Ensino Infantil, Ensino Fundamental, Educação de Jovens e Adultos. É administrado pela Secretaria Municipal de Educação da Prefeitura de São Paulo e, em cada equipamento, há uma Gestão local composta por Núcleos de Educação, Esportes e Cultura. A infraestrutura aloca, entre outros ambientes, uma Biblioteca Pública e Escolar (Híbrida). Atualmente, a cidade de São Paulo possui 46 CEUs. Para conhecer melhor, indicamos a dissertação de Charlene K. Lemos, intitulada: Usos e apropriações das bibliotecas dos Centros Educacionais Unificados: práticas bibliotecárias de mediação informacional e cultural.

Disponível em: <http://www.teses.usp.br/teses/disponiveis/27/27151/tde-10012013-184342/pt-br.php>. Acesso em: 12 mar. 2015.
} 
Estação do Conhecimento Einstein, sob a hipótese de que tais práticas, tal como realizadas e propostas por esse dispositivo cultural, incluem componentes de ludicidade, indispensáveis ao chamado protagonismo cultural (PERROTTI, 2008).

O desenvolvimento da pesquisa incluiu pesquisa bibliográfica, tendo em vista o estudo do conceito de lúdico, com o intuito de compreendê-lo em diferentes abordagens, de modo a obter referências que ajudassem a observar a complexidade do fenômeno em questão. Nesse sentido, buscamos elementos que pudessem nortear nossas análises acerca das formas como o ato de conhecer se manifestaria nas relações entre sujeitos e dispositivo informacional, não somente sobre o que o jogo propiciava objetivamente. $E$, se a questão do lúdico é controversa em instituições voltadas para crianças e jovens, conforme assinala Perrotti (1990), por que não inclui-lo ou considerá-lo na prática de relação dos sujeitos com os signos, elemento indispensável nas dinâmicas do conhecimento? Por que não um novo conceito de lúdico que desse sentido às ações específicas das bibliotecas?

A metodologia do estudo também incluiu a realização de uma pesquisa de terreno, empírica, tendo em vista identificar em que condições o ato lúdico poderia se objetivar no contexto específico da relação dos sujeitos com o universo simbólico, ou seja, extrapolando a noção imediata do jogo enquanto tal. Nesse sentido, o Programa Aprendendo a Pesquisar (PAP), realizado pela Estação do Conhecimento Einstein $\left(\mathrm{ECE}^{2}\right)$ Paraisópolis, anteriormente referida, foi tomado como objeto empírico do estudo. Além de acompanhar de modo sistemático a realização dessas ações junto a diferentes grupos, o estudo incluiu coleta de dados, por meio de depoimentos dos próprios protagonistas do processo - participantes de diferentes idades, educadores e mediadores tendo em vista conhecer o significado dos processos experimentados, no âmbito do PAP.

Do mesmo modo, o estudo buscou sistematizar a noção de dispositivo informacional dialógico, dada a sua essencialidade na compreensão das distinções entre o conceito de um dispositivo informacional dialógico, regido por premissas da apropriação cultural dos dispositivos culturais historicamente pautados por objetivos de difusão cultural (perspectiva que, de resto, orienta historicamente as bibliotecas públicas, entre nós). Estabelecer estas distinções permitiria compreender que a organização, os tipos e modos de desenvolvimento das práticas, as formas de relação da biblioteca com seus contextos, ou seja, a sua ordem informacional, afeta os processos de relação dos sujeitos com 0 conhecimento e a cultura. O entendimento de que o hiato comunicacional apontado - o enorme distanciamento entre grupos populacionais e os ambientes de informação, ou ainda, uma perspectiva de usos limitados -

\footnotetext{
2 Pautada por concepções e configurações materiais da ordem informacional dialógica (PIERUCCINI, 2004), a ECE, além de se constituir como espaço laboratorial do Colaboratório de Infoeducação (Colabori), Grupo de pesquisa ligado aos estudos da Infoeducação, ao qual somos filiados, está preparada para o desenvolvimento de pesquisa que visam construir referenciais acerca das relações entre dispositivos informacionais e apropriação cultural.
} 
permitiria, assim, a construção de um novo olhar para a as inevitáveis e urgentes redefinições para os ambientes de informação e cultura em nosso país. Esta premissa, de resto, inscreve-se nos princípios que regem a Infoeducação, área de estudo e de práticas sociais voltadas às relações inextricáveis entre Informação e Educação (PERROTTI, PIERUCCINI, 2007, p.46)

\section{0 conceito de lúdico: para além de uma compreensão imediata}

Partindo-se do pressuposto de que a apropriação da informação implica relações críticas e criativas com o universo simbólico em sua totalidade, e que tais relações não se constituem naturalmente, mas, ao contrário, demandam aprendizagens orgânicas, sistemáticas e continuadas, tendo em vista a construção de saberes informacionais (PERROTTI, 2008), a abordagem da noção de lúdico, incluída sob a perspectiva desta pesquisa, procura a identificação de categorias que possam favorecer processos de construção de relações com 0 Conhecimento e a Cultura.

Diante desses objetivos, o exame da literatura especializada ${ }^{3}$ permitiu-nos a elaboração de um ensaio conceitual ampliado sobre as abordagens da noção de lúdico, buscando-se identificar referências que explicitem o papel do ato lúdico como categoria biológica, social, cultural e histórica. Nesse sentido, recuperar sua compreensão em noções imediatas (jogo, divertimento, lazer) e revelar outras (desejo, criatividade, espontaneidade, envolvimento) forneceu elementos para ampliar o entendimento do quadro que o implica.

Conforme afirma Campos (2008, p. 2), se Johan Huizinga não é o pioneiro dos estudos do amplo conjunto de abordagens socioculturais que inclui passatempos, recreações, brincadeiras, jogos e esportes ${ }^{4}$, no entanto, pode ser considerado como o primeiro a encetar esforços no sentido de conceituar o termo no campo das Ciências Humanas. Segundo o autor, "[...] poderíamos considerá-lo uma atividade livre, conscientemente tomada como 'não séria' e exterior à vida habitual, mas ao mesmo tempo capaz de absorver o jogador de maneira intensa e total. É uma atividade desligada de todo e qualquer interesse material, com a qual não se pode obter qualquer lucro, praticada dentro de limites espaciais e temporais próprios, segundo uma certa ordem e certas regras. Promove a formação de grupos sociais com tendência a rodearem-se ao resto do mundo por meio de disfarces ou outros meios semelhantes" (HUIZINGA, 2010, p.16).

Esta síntese, postulada em 1938, é defendida ao longo de sua obra, referência seminal e obrigatória aos estudos contemporâneos concernentes à ideia que perpassa a noção de lúdico. Nesse sentido, retomá-la ajudou a identificar aspectos importantes em relação ao estudo

${ }^{3}$ HUIZINGA (2010); CAILLOIS (1990); BROUGÈRE (1998); KISHIMOTO (2013); LOPES; TEIXEIRA (2005); MASTROCOLA (2012); ARANA (1996); JULIA (1969); CUNHA (2003), entre outros.

${ }^{4}$ Friedrich Schiller no campo da Filosofia; Herbert Spencer, na Psicologia (CUNHA, 2003); Friedrich Fröebel e Susan Blow na Educação, podem ser indicados como seus precursores (KISHIMOTO, 2013). Walter Benjamin (2002), também trata de questões relacionadas ao univeso do lúdico, em diversas publicações realizadas na década de 1920. 
em causa, como meio de elencar categorias que permitem identificar a ocorrência do fenômeno em contextos concretos, tal como nos interessa no contexto do jogo do aprender a conhecer, disposto na noção de saberes informacionais (PERROTTI, 2008).

Numa perspectiva sociológica, o termo é compreendido dentro do conceito de "sociação" (SIMMEL, 2006) em relação às dinâmicas de formação de grupos (crianças e adultos). Articulado pela força de interesses individuais (sensoriais, ideais, momentâneos, duradouros, conscientes, inconscientes, casuais, determinados) ou finalidades (conquista, caça, competição, caprichos), o ato lúdico revela-se de modo plural: encontros, hábitos, festividade, repetição e vínculo. Conforme Simmel (2006, p. 75), "[...] a sociabilidade como forma lúdica, transforma elementos de individualidade (inteligência, desejo, criatividade, afetividade) em formas de estar com o outro e de ser para o outro". Como linguagem, o lúdico apresenta uma codificação, ou seja, um sistema de regras ou de ordem. Assume um sistema linguístico, explícito ou implícito, cuja natureza pode ser absoluta: expor uma estrutura sequencial, de sucessão e recuo; de apreensão objetiva ou instrumental; estruturada e não estruturada (flexível); de criação e recriação, comprometida, incerta, desafiadora. Como atividade ou ocupação voluntária o lúdico tem, como principais predicados, a espontaneidade e o protagonismo; de outro modo, pode se revelar num conjunto de elementos de ordem estética: equilíbrio, equidade, contraste, variação, solução, ritmo e harmonia.

Necessariamente, 0 ato lúdico se constitui num ambiente situacional ("um círculo mágico") material (um lugar, um objeto, um suporte) ou imaginário (fictício), determinado ou autônomo, instável e interpenetrante, marcado por limites temporais e espaciais, porém, lócus privilegiado para experiências inéditas e aprendizagens, especialmente, adequadas ao protagonismo: decisão de entrada, permanência e abandono; aprimoramento de aptidões e habilidades; tenacidade; crítica e criação; identidade; autoconfiança, autocontrole e improvisação. Ademais, também se revela ambivalente e simultâneo, pois provoca e suspende desejos; causa prazer e desprazer; produz adesões e recusas; se realiza por meio de sucessão e interrupção, de integração e desintegração, de união e desunião, jogo e não jogo, protagonismo e antagonismo; aproximação e distanciamento. É ação, ao mesmo tempo, ocioso e ativo. Traz como corolário a "lei da repetição", o "querer novamente" (BENJAMIN, 2002, p. 101).

Diante isso, aspectos como intensidade, excitação, entusiasmo, absorção, paroxismo, prazer, fruição, imaginação, concentração, expressividade, criatividade, ambivalência se revelam constituintes da significação lúdica e são manifestos na brincadeira, no jogo, na comunicação, na construção de artefatos digitais ou analógicos. Conforme assinala Brougère (1998), o jogo é sempre um espaço de incerteza. Tanto a finalidade como os resultados finais destas atividades são sempre desconhecidos, imprevisíveis. Jogar é não saber o resultado mesmo que se tenha preparado um itinerário, ou calculado seus efeitos. Esta assertiva se aplica diretamente à noção de pesquisa implícita na ideia de 
conhecimento e significação: o sujeito percorre trilhas, mas o seu desejo de conhecer o leva por caminhos inusitados...

\section{A "pesquisa" em âmbitos educativos: questionamentos}

O desinteresse pelos objetos culturais observado no contexto específico de uma biblioteca pública inclui-se em problemática mais ampla que engloba tanto aspectos das dificuldades de se lidar com as informações ali disponibilizadas, como também de desconhecimento das lógicas específicas que rege a ordem do dispositivo, bem como dos frágeis vínculos culturais com a Biblioteca em nosso país e que se reflete em desconsideração sobre o valor desse organismo para a construção de conhecimentos e saberes específicos, fundamentais à construção do conhecimento. Na medida em que esta situação afeta direta e concretamente as relações de crianças e jovens com o universo dos signos, objetivadas em práticas cotidianas, como por exemplo, na realização de pesquisas escolares, vale abordar aspectos relacionados a esta prática, uma vez que as relações entre a biblioteca e, sobretudo, estudantes - crianças e jovens, especialmente - é favorecida majoritariamente, por via de obrigações escolares dessa natureza.

De acordo com Burke (2003), os institutos e organizações de fomento às pesquisas surgiram no século XVIII. É no bojo das transformações que vinham ocorrendo que surge a própria noção de "pesquisa" 5 , ligada às universidades, posteriormente expandida pelos ideais iluministas de conhecimento.

Em termos técnicos, o Dicionário Básico da Língua Portuguesa assinala que "pesquisa" significa "[...] indagação ou busca minuciosa para averiguação da realidade; investigação e estudo minudentes e sistemáticos, com o fim de descobrir ou estabelecer fatos ou princípios relativos a um campo qualquer do conhecimento" (FERREIRA, 1986, p. 502).

Atualmente, no que concerne à "pesquisa escolar", Bezerra (2008) isola alguns elementos presentes na Lei de Diretrizes e Bases da Educação - LDBs (BRASIL, 1997) e nos Parâmetros Curriculares Nacionais $\mathrm{PCNs}^{6}(1997)$ explicitando como esta prática deve ser desenvolvida em âmbitos educativos tradicionais. Segundo a autora, a pesquisa escolar é instrumento didático, dirigido aos educadores e educandos, geralmente realizada por meio de projetos constituídos de uma sequência de etapas metodológicas acerca de um objeto, com intuito de aprofundamento temático e fins de "familiarização" para usos posteriores, especialmente,

\footnotetext{
${ }^{5}$ A palavra "pesquisa" em diversas línguas (research, recherche, ricerca etc.) deriva da origem comum "busca" (search etc.) e pode ser encontrada em títulos de livros já no século XVI, inclusive nas Recherches de la France (1560). Junto com a palavra "pesquisa" outros termos vieram a ter uso regular, notadamente "investigação" (e seu equivalente italiano indagine), que se ampliou para além de seu contexto legal original, e "experimento" (em italiano, cimento), que se restringiu a partir de seu sentido original de teste em geral para o de teste das leis da natureza em particular. (BURKE, 2003, p. 48)

6 Parâmetros Curriculares Nacionais: proposta de reorientação curricular da Secretária de Educação Fundamental do Ministério de Educação e do Desporto como referência curricular nacional, garantindo a todo aluno de qualquer região do país o direito de ter acesso aos conhecimentos indispensáveis para a construção de sua cidadania (1997).
} 
no curso da vida acadêmica (iniciações científicas, pós-graduações etc.), ou seja, instrumentalização e objetivação efetiva sobre tais domínios, submetidos a um conjunto de interesses outorgados de antemão.

Tal como indicado por Joseph Jacotot ${ }^{7}$, retomado por Rancière (2011), desde a Revolução Francesa em 1830, a instituição pedagógica (a educação formal) tem se constituído como lugar - material e simbólico onde prevalece o exercício da autoridade e de submissão dos sujeitos. Tal instituição objetiva a progressão destes sujeitos até o limite de suas capacidades, oferta o conhecimento das matérias do programa para a maioria, mas a capacidade de se tornar mestre, por sua vez, apenas aos 'melhores'.

No contexto atual, a noção de pesquisa que mantém como precedente esta relação tradicional entre sujeitos e instituições (dispositivos) corrobora para permanência do "monopólio do conhecimento", assertiva da educação iluminista, arraigada em nossa cultura. Nesse sentido, a "busca de informação" (a pesquisa) tem resultado de demandas decorrentes de práticas educativas ou culturais estabelecidas, ou demandas pontuais, cujos objetivos são prescritos e anódinos. A pesquisa, sob tal abordagem, permanece, portanto, inscrita em paradigma que privilegia a difusão da informação, favorecendo, em decorrência os processos de homogeneização e de assimilação cultural.

Nessa conformação, os sistemas educacionais reforçam a desigualdade social a ser reduzida, mas que ao cabo, se reproduz indefinidamente. Assim, instituições reguladoras da ordem, especialmente as instituições educativas (nas quais se incluem as bibliotecas públicas, escolares), mantêm em sua base, não uma instrução emancipadora (que tem a compreensão da igualdade, por princípio), mas a formação e a manutenção de elites, inserção social por meio de convenções e agenciamentos pré-estabelecidos e controlados.

Face a isso, "[...] é preciso uma inversão dessa concepção educadora, é preciso tomar a igualdade como um pressuposto, forçar uma capacidade que se ignora ou se denega a se reconhecer, e desenvolver todas as consequências desse reconhecimento" (RANCIÈRE, 2011, p.12).

Tais princípios, todavia, demandam configurações objetivas, inscritas na prática concreta, cotidiana, da vida dos organismos de educação e cultura. Seguindo as orientações postuladas por Morin (2004), para quem o desafio está em se conseguir reformar o pensamento, reformulando os modos de compreender e inventar caminhos ao ato de conhecer, o enfrentamento desse problema sociocultural introduz perspectivas de intersecção e de investigação comum entre os campos da Informação e da Educação, tal como desdobrado, a seguir.

\footnotetext{
${ }^{7}$ Em sua obra, Rancière não especifica as fontes documentais consultadas sobre o método de Jacotot. Javier Suso Lopez (2003) nos oferece um panorama das obras essenciais Joseph Jacotot acerca da temática de que trata Rancière. Disponível em: < https://dhfles.revues.org/1608 >. Acesso em: 12 mar. 2015.
} 


\section{A EC e o PAP: os contextos do estudo}

\subsection{A ECE: um dispositivo informacional dialógico}

O Programa Aprendendo a Pesquisar e a Estação do Conhecimento Einstein mostraram-se relevantes a este estudo, porque permitiram observar ambientes, processos e práticas de pesquisa norteados por princípios que entendem os estudantes como sujeitos do conhecimento e a pesquisa como ato de criação simbólica.

O conceito de Estação do Conhecimento (EC), que deu origem ao projeto na sua instituição mantenedora (Sociedade Beneficente Hospital Albert Einstein) é definido como "[...] ambiente especialmente preparado para a apropriação sistemática de saberes informacionais, indispensáveis aos processos de construção de conhecimento na contemporaneidade" (PERROTTI; VERDINI, 2008, p. 16). Trata-se de conceito norteador à formulação de novas configurações concretas, palpáveis, objetivas, reunindo diferentes mídias e processos educacionais e culturais, como também, instância planejadora, articuladora e implementadora de recursos e processos culturais previamente existentes.

Assim, a EC Einstein Paraisópolis ${ }^{8}$ é um dispositivo informacional dialógico voltado ao desenvolvimento de programas visando a apropriação cultural, distinguindo-se, desse modo, daqueles que se pautam por concepções de difusão do conhecimento, caracterizados como meros suportes de informação.

Com base na perspectiva foucaultiana, o conceito de dispositivo, é tomado como signo, "[...] mecanismo de intervenção sobre o real, que atua por meio de formas de organização estruturada, utilizando-se de recursos materiais, tecnológicos, simbólicos e relacionais, que atingem os comportamentos e condutas afetivas, cognitivas e comunicativas dos indivíduos" (PIERUCCINI, 2004, p. 56). O conceito de dispositivo, nessa perspectiva, refere-se à noção de dispositivo tecno-semio-pragmático (PERAYA, 1999) e, associado à ideia de ordem informacional (lógica que orienta as relações socioculturais) oferece referenciais importantes para fazer avançar concepções limitadas acerca da biblioteca em contextos educativos. Tal compreensão, assim, supera e contrapõe-se à visão idealista, donde o conhecimento depende exclusivamente do domínio de conteúdos, indicando de modo evidente o papel dos dispositivos na significação do conhecimento. A premissa permite evidenciar que a ordem informacional assentada sobre princípios dialógicos, atua sobre processos de apropriação do universo sígnico pelos sujeitos, confirmando hipóteses anteriores, acerca das relações entre a ordem informacional e a apropriação simbólica (PIERUCCINI, 2004).

\footnotetext{
${ }^{8}$ Implantado por meio de parceria entre a Sociedade Beneficente Israelita Albert Einstein e o Colaboratório de Infoeducação, instância de pesquisa do Departamento de Biblioteconomia e Documentação, da Escola de Comunicações e Artes da Universidade de São Paulo, sob a coordenação acadêmica da Profa. Dra. Ivete Pieruccini e direção científica do Prof. Dr. Edmir Perrotti.
} 


\subsection{O Programa Aprendendo a Pesquisar (PAP): dados elementares}

Iniciado em 2011, o PAP tem a participação de 120 crianças e jovens da Estação do Conhecimento Einstein (composto por grupos heterogêneos: meninas e meninos com idades entre 7 e 15 anos), e atua na perspectiva de implantar uma nova modalidade educativa, que visa orientar cada participante para que construa "o seu próprio projeto de conhecimento".

O PAP reúne projetos de pesquisa individuais (ou, eventualmente, realizados por pequenos grupos), a partir de interesses próprios, e orientados pelo desejo de conhecer os mais variados assuntos. Todo o processo é orientado pelos educadores do Núcleo de Educação do Programa Einstein na Comunidade de Paraisópolis, mas os participantes têm liberdade de escolher seus temas, de organizar e planejar suas pesquisas, de definir ritmos, redefinir trajetórias, se auto-organizarem, interromperem ou substituírem seus projetos por outras pesquisas, retomando-os posteriormente, ou não. Não há demandas/pressões externas, uma vez que o PAP não se pauta por programas curriculares de ensino - e, assim, pode estabelecer suas próprias estruturas e dinâmicas de funcionamento. Tais dinâmicas são acompanhadas tanto pelas infoeducadoras (não coordenam grupos específicos), com domínio privilegiado do dispositivo informacional, e pelas educadoras das turmas que, como as primeiras, prestam-se às mediações interpessoais, indispensáveis às continuidades das dinâmicas de apropriação.

Por princípio, cada participante trabalha durante três meses sobre um tema, período em que se debruça sobre os recursos internos e externos (internet e comunidade) existentes, lendo, conhecendo suas respectivas naturezas, indagando-se sobre o que tem em mãos, mas também sobre as ausências, o que não têm. Estes aspectos que orientam as dinâmicas do PAP evidenciam a natureza dialógica que o caracteriza, diferenciando-o dos modelos tradicionais, sobretudo, pautados por práticas educativas difundidas em nosso país, que, ademais, permanecem reservadas a um ensino conteudista e transmissivista, ou ainda, sob a concepção de práticas que objetivam resultados esperados.

Essa opção metodológica proposta pelo PAP articula-se ao pressuposto de que há aprendizagens fundamentais ao ato de pesquisar um jogo do conhecimento - "[...] que demandam saberes especiais e específicos, extremamente complexos, que não se sustentam no empirismo que muitas vezes orienta práticas culturais desta natureza, quando o que está em causa, é a apropriação e não a assimilação de informação" (PASSOS; PIERUCCINI, 2013, p. 634).

Para tanto, a ideia de pesquisa associada ao conceito de saberes informacionais (PERROTTI, 2008), tomado como conjunto complexo de habilidades, competências e atitudes face à informação e indispensáveis à sobrevivência individual e coletiva nas sociedades da informação ajuda a compreender as intenções do Programa. No sentido referido, os saberes 
mostram-se compatíveis à ideia de pesquisa como jogo do conhecimento, pois, ao se constituírem, ao mesmo tempo, como instrumentais e essenciais, transversais e específicos, procedimentais e conceituais, viabilizam e instigam as múltiplas variáveis implicadas nas relações dos sujeitos com a ordem do conhecimento. Por esta razão, na perspectiva da apropriação cultural (e não apenas o uso da informação, tendo em vista uma demanda), trata-se também de apropriar-se da ordem, em outras palavras, de saber jogar o jogo da informação e do conhecimento, questão fundamental porque favorece ao sujeito refletir sobre a natureza e os processos de tais conhecimentos e ações, superando visão instrumental e reduzida de pesquisa e dos correspondentes usos dos dispositivos informacionais para o acesso e consumo de signos.

Essas distinções permitiram evidenciar e orientar a pesquisa no intuito de nos voltarmos para as relações sujeitos-informação-dispositivo informacional, uma vez que a apropriação/significação, na perspectiva adotada, demanda, com claras evidências, movimento, ao mesmo tempo, objetivo e subjetivo.

\section{Revelações dos atos lúdicos de conhecer: sínteses}

Nessa pesquisa exploratória, de natureza qualitativa, os dados foram coletados por meio de registros sonoros (dos depoimentos), registros visuais (fotográficos e audiovisuais dos sujeitos e atividades), transcrições dos áudios e notas de campo realizadas em 2013, após períodos de observação direta (apresentação pessoal, conversas e participação nas atividades) e indireta (acompanhamento de atividades das educadoras e mediadoras na ECE), considerando-se tanto as educadoras do PAP (6), as infoeducadoras (2), a coordenadora do Programa, jovens dos grupos etários de 9 a 11 anos e 12 a 15 anos (turmas da manhã e tarde) que realizam as oficinas do Programa Aprendendo a Pesquisar (num total de 15 crianças).

Considerando-se o PAP, bem como a ECE, os depoimentos dos diversos sujeitos implicados no contexto foram revelando e apontando elementos que implicam o papel mediador do dispositivo informacional dialógico (ambiente, repertórios, sujeitos) e as concepções especificamente do Programa nos processos envolvendo o jogo do conhecimento, que envolve, dentre outros aspectos, a construção tanto de habilidades (saberes operacionais), como competências (saberes conceituais), mas, sobretudo, atitudes (saberes axiológicos), conforme Perrotti e Pieruccini (2007).

De modo objetivo, a pesquisa interessou-se em observar e salientar situações e processos de uso e apropriação dos recursos materiais, destacados pelos próprios sujeitos da pesquisa. Traduzidos em categorias que possam caracterizar-se como referências ao campo científico, evidenciamos: o complexo papel das linguagens informacionais e da organização física dos recursos como trilhas para penetração no universo da informação organizada; o papel dos infoeducadores nos processos de mediações pedagógicas e reflexão crítica sobre o ato de pesquisar; 0 
papel pedagógico da pesquisa como prática dialógica de construção e comunicação do conhecimento; e a noção de conhecimento como um jogo colaborativo.

Os relatos são significativos no sentido de que a ordem do dispositivo proposta é inclusiva, evidenciando que o jogo do conhecimento, ato lúdico de autoregulação e organização, implica sujeitos que conheçam as "regras" e que também possam atuar sobre elas.

Um primeiro passo em relação à busca dos materiais é processo complexo na dinâmica do ato de conhecer, uma vez que implica apropriação das relações entre o que o sujeito deseja encontrar e o modo como os objetos e a informação estão organizados. Além de domínio de lógicas abstratas, o processo requer concentração, tenacidade, habilidade, crítica.

Nesse sentido, dois depoimentos iniciais são representativos das modulações presentes na ECE: "[...] a EC é bem organizada, tem uma separação dos livros... é mais fácil de encontrar. O interessante é que os autores são separados por letras. Fica mais fácil da gente achar o livro que a gente procura..." (Menino 11, 12 anos).

O comentário do jovem evidencia um estágio de relação autônoma e de domínio de linguagens implícitas e explícitas no dispositivo. As possibilidades de autonomia são decorrentes de dinâmicas contínuas, de mediações que integram ações realizadas com os grupos desde muito cedo, conforme assinala uma educadora:

[...] eu percebo que eles vão sim pras estantes menores. Eu acho que também é a questão de como o livro está disposto, porque para as [crianças] menores, o livro não fica assim, enfileiradinho, que você só vê a lombada e etiqueta. Ali, tem como você manusear, ver a capa. Eles querem ver a capa do livro! É primeira coisa que a criança vê: a capa! (Educadora 4).

Conforme reforça uma das infoeducadoras ouvidas na pesquisa:

[...] depois [de um tempo] eles já sabem onde fica tal coisa que eles gostam, eles já têm um conhecimento maior do espaço: "eu gosto mais dos livros de um autor, então, eu já sei mais ou menos onde está". "Gosto mais de HQ? Então ele já sabe que tem ali no cantinho, gibis. Eles vão se organizando, mas é intenso no início, até eles entenderem (Infoeducadora 1).

Localizar o que se deseja dentre materiais acessíveis a todos, percorrendo o ambiente, faz parte das dinâmicas já previstas na ECE. O contato direto, irrestrito, é categoria que integra a perspectiva da imersão dos sujeitos no ambiente informacional dialógico. Esse contato direto joga com os estímulos à participação nos processos de aprendizagem, desinibe, autoriza, e saber fazer escolhas, para além do manuseio, implica linguagens que "contem, digam onde os materiais estão dispostos". 
Assim, num outro nível, mais complexo, ligar o local físico dos objetos aos conteúdos que armazenam - a informação - é uma etapa do jogo que demanda iniciação, permanência, repetição e insistência. Os próprios educadores reconhecem que a linguagem de organização atua nas dinâmicas de apropriação da ECE e que saber o seu significado, suas lógicas são aspectos decisivos a todos, incluindo os próprios educadores, conforme afirma a Educadora 4:

Eu frequentei bibliotecas e livrarias em que [o material] está separado [...] mas não por cor assim. Por cores, igual é [na ECE] é mais lúdico, e isso pra criança é muito bom, principalmente as que não são alfabetizadas. A cor é muito importante, como ela ainda não se apropriou dessa linguagem, desses códigos. Então, ela tem um código que é a cor. Ela reconhece as cores, então, ali fica mais fácil.

Figura 1 - Classificação de autores (acervo de livros infantis)

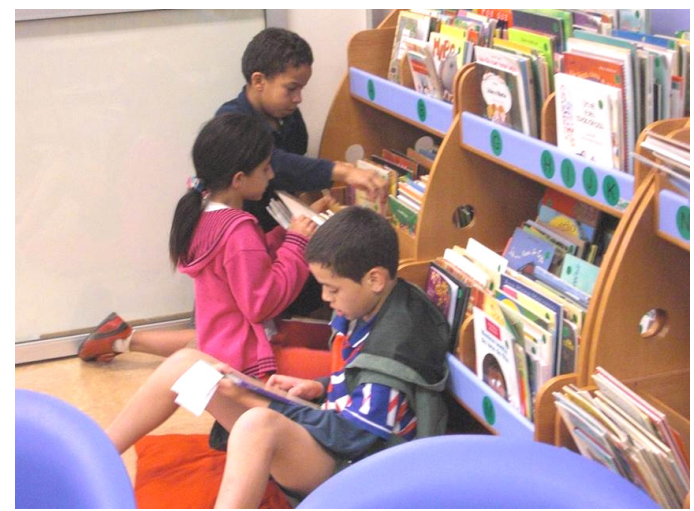

Fonte: Núcleo de Educação do Programa Einstein na Comunidade de Paraisópolis.

Já, para uma infoeducadora, os processos de construção da autonomia dos jovens também se evidenciam pelo desafio, pelo estímulo à reflexão, uma espécie de jogo relacional entre temas e a ordem do dispositivo: "Por exemplo: o adolescente vem e fala: "aí, eu estou pesquisando sobre DST". Eu respondo: "DST é o quê? É uma doença? Doença é o que? Saúde? Aonde fica Saúde? Que cor está?" (Infoeducadora 2).

Essas perguntas - jogo de indagações - vão estruturando e fornecendo elementos para as intervenções, de caráter pedagógico, no sentido de explicitar lógicas e recursos à compreensão não apenas de regras, mas do sentido dos elementos que constituem o dispositivo dialógico. Alguns depoimentos permitem exemplificar como apropriação e práticas de mediação significativas vão se dando:

"Lá em cima, na Estação [do Conhecimento] tem um painel explicando o que é... tipo (sic] o verde é... Literatura ... Literatura Infantil!" (Menino 10, 12 anos). Ao que outro jovem complementa: "Cada cor tem um significado" (Menina 2, 10 anos). 
No encontro, a própria noção de compartilhamento vai se explicitando: "Tem a bolinha preta, tipo (sic), que é de pesquisa [obras de referência]... a amarela é, tipo assim, a Cinderela, Peter pan, essas coisas... a bolinha amarela, é de Artes..." (Menina, 9 anos).

As imagens a seguir ilustram os depoimentos:

Figura 2: A Classificação Cromática da ECE

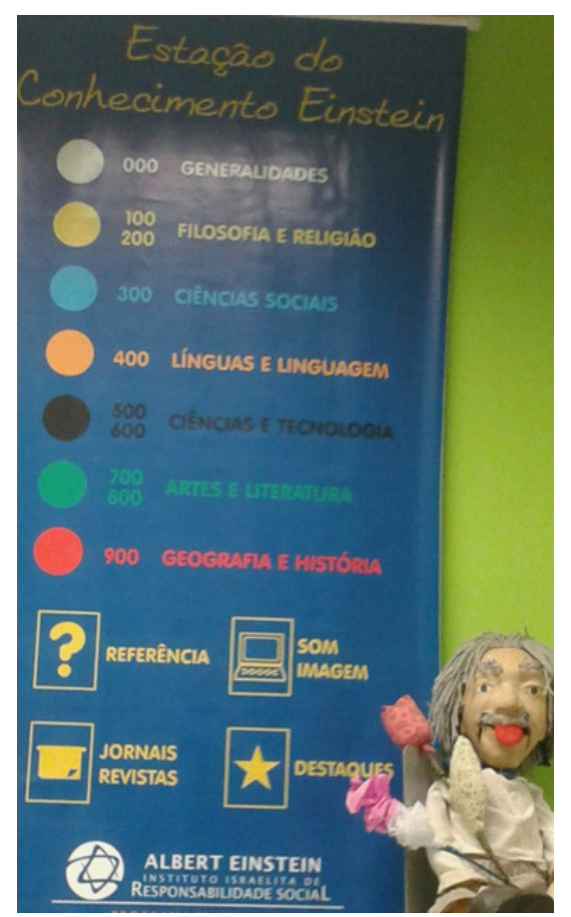

Fonte: Núcleo de Educação do Programa Einstein na Comunidade de Paraisópolis

Figura 3: Representação temática: instrumento de linguagens documentárias (PAP)

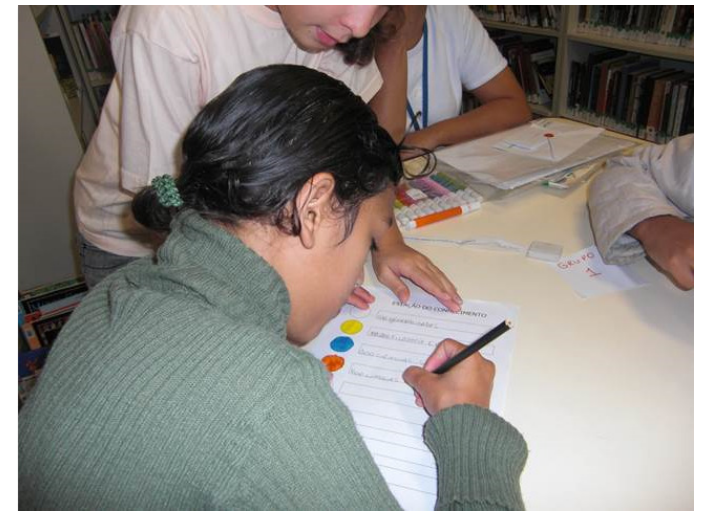

Fonte: Núcleo de Educação do Programa Einstein na Comunidade de Paraisópolis

As possibilidades de relação lúdica, criativa, com o conhecimento, no quadro das práticas propostas, são favorecidas por mediações intrínsecas (configuração, linguagens do dispositivo) e extrínsecas (explicações e associações oferecidas pelas infoeducadoras). Por conseguirem participar e penetrar nos sentidos da ordem informacional dada, crianças e jovens redefinem sua posição no jogo do conhecimento. Em outros termos, não 
somente usam o espaço, mas aprendem com ele que a informação está estruturada em códigos, que funcionam como chaves de acesso ao universo simbólico.

A partir desta perspectiva, o processo de pesquisa, sob o enfoque adotado pelo PAP, demonstrou implicar tanto gestões para garantir as dinâmicas funcionais dos usos coletivos da ECE, quanto processos que entendem $o$ ato de conhecer como experiência com os signos e em relação entre sujeitos, de modo livre, sem inibir ou impedir a ida, o contato, os usos em momentos alternativos aos grupos. A constatação deste movimento remete às colocações sobre ideia de construção do "círculo mágico", formulada por Huizinga (2010). Segundo o autor, "[...] dentro do círculo mágico, as leis e costumes da vida cotidiana perdem validade. Somos diferentes e fazemos coisas diferentes". Apesar dessa aparente desconexão com a realidade, o jogo é mais do que um reflexo psicológico e ultrapassa os limites da atividade puramente biológica ou fisiológica: "[...] é uma função significante que encerra um determinado sentido, pois alguma coisa transcende as necessidades imediatas e confere sentidos para as ações" (HUIZINGA, 2010, p. 16). Dessa observação, Mastrocola (2012, p. 24) enfatiza que as experiências vividas dentro do círculo mágico "[...] representam algo para aqueles que participam delas - envolve experiências e significados que permanecem com o indivíduo, que por sua vez as carrega de volta para o cotidiano". Conforme defende, mais do que um lugar de entretenimento, o "círculo mágico" refere-se à "experiência de aprendizado". (grifo nosso).

Assim, conforme nos explica uma infoeducadora:

Em todas as atividades que a gente desenvolve na Estação [ECE]... isso é muito forte... 'Olha, eu achei isso!'... 'Ah, quem está pesquisando sobre isso? Quem está procurando isso?'... 'Vai lá... leva pra ele!' Isso é muito comum... de um estimular o outro... (Infoeducadora 2).

Tal processo é efetivo e parece atuar como forma de consolidar uma prática, muitas vezes aborrecida ou competitiva entre alunos no ensino formal. No PAP, entretanto, as concepções caminham num outro sentido, qual seja, o da colaboração, da cooperação, da cumplicidade, da construção de vínculos e de atitudes, que extrapolam a dimensão objetiva do ato de conhecer:

Às vezes, uns dois escolhem o mesmo tema... eles têm essa liberdade de fazer juntos... um pode ajudar o outro... não tem uma regra assim... eles podem ajudar um ao outro sim... e pode fazer sozinho (Educadora 1 ).

Estas possibilidades estão assentadas numa concepção de gestão pedagógica da ECE. Segundo a coordenadora do Núcleo de Educação: "Isso, aqui, é contínuo. Tem aqueles que ficam, que estão conosco desde o começo do projeto. Tem os outros que saem, depois, tem os outros que vêm outra hora, aqueles que voltam". 
Observar e compreender as relações dos sujeitos - jovens - com seu desejo de conhecer, de imergir, de envolverem-se em seus projetos de conhecimento faz parte do apoio aos processos de pesquisa, na perspectiva lúdica. O depoimento de um jovem permite explicitar elementos lúdicos presentes nas práticas de pesquisa. Estes elementos referem-se à posição protagônica, face às trilhas incertas do conhecimento: à decisão da entrada (escolha de um tema de pesquisa), à busca de materiais e coleta de fontes informacionais (permanência) e de recuo (abandono) sobre a temática:

A pesquisa, assim, que eu mais gostei de descobrir foi sobre... a pesquisa que eu fiz sobre a ponte de safena, que está em cardiologia. Nessa pesquisa... até hoje eu não consegui terminar porque tenho que me aprofundar bastante. Tenho que ter bastante conhecimento. Assim, eu não tive a oportunidade de fazer. Na verdade, eu desisti. (Menino 10, 12 anos).

De fato, muitas são as razões (conscientes ou inconscientes) que levam os sujeitos a projetarem-se nas tramas do conhecimento, razão pela qual programas que envolvam a prática de pesquisa precisam necessariamente concebê-la como como ato significativo, e não meramente procedimental. Ademais, vale ressaltar que depois de muito tempo, soubemos (do próprio menino), que seu tema de pesquisa teve como origem a preocupação com uma cirurgia que seu pai adotivo faria no correr daquele ano. Independentemente das expectativas de que o tema de pesquisa possa ser retomado em outro momento, podemos assinalar que o ato lúdico de conhecer se inscreve diretamente na natureza simbólica do conhecimento e, evidencia, assim, sua natureza transdisciplinar e dialógica, que transfigura-se em temas de interesses propostos pelos jovens, acolhidos posteriormente pelos educadores $\mathrm{e}$ levados à efeito no PAP.

As dinâmicas observadas no terreno mostraram, ainda que a pesquisa, na perspectiva lúdica admite modalidades plurais. Grupos que pesquisam juntos, mas cada qual com seu respectivo tema, propiciam não apenas modo particular não apenas de construção coletiva dos saberes, mas de construção de identidades e incentivo ao ato de conhecer, conforme revela uma infoeducadora:

Ah... um influencia o outro, que é engraçado: 'olha, o que eu achei!' Um mostra pros outros, eles fazem grupos, eles comentam entre eles 'olha o que eu achei!'... 'Olha que interessante!'... além de mostrar pra gente... eles mostram um pro outro... 'Olha, isso é a sua cara!' Uma troca (Infoeducadora 2). 
Outra infoeducadora também sinaliza essas trocas de conhecimentos: "Olha, você vai pesquisar isso? Esse está aqui nesse livro!". "Eles que vão escolhendo, acho que isso também dá uma liberdade, um prazer..." (Infoeducadora 1 ).

Não somente a ajuda ao outro, mas também o envolvimento, a festa em torno dos achados, das conquistas com as próprias descobertas é possibilidade de estímulo, colaboração, incentivo às buscas dos colegas: "Eles não conseguem se conter quando descobrem uma coisa legal, eles já saem gritando pra todo mundo, vai mostrando, mostra o livro. Os outros também têm interesse em ver o que o outro está fazendo" (Educadora 2). Não é assim que as equipes comemoram o gol? Ou o xeque-mate num torneio por equipes estudantis?

Em suma, a pesquisa, na perspectiva assinalada pelo PAP inclui mediações pedagógicas que se orientam pela construção de vínculos entre os sujeitos do conhecimento, o ambiente e seus repertórios, como forma de comunicação e relação de mútuo apoio entre os pares. Nesse sentido, a participação das infoeducadoras mostrou-se fundamental nos processos de pesquisa sustentando objetivamente a concepção dialógica, que faz das dinâmicas com o conhecimento, um ato lúdico. Os participantes percebem com clareza e explicitam tais distinções em relação a outros contextos, destacando que o modo de relação é fundamental para o interesse em protagonizar atos de conhecimento. As evidências em relação ao modo como tais mediações são realizadas, priorizando-se o espaço de liberdade, de decisão, de criação e de crítica do conhecimento, bem como a construção de habilidades, aptidões, autonomia e atitudes face à informação mostram-se constantemente remarcáveis, portanto, aberta aos desejos e aos sentidos que os sujeitos imprimem às atitudes com que encaram o ato de pesquisar. Dito de outra forma, retomando um postulado de Barthes (2007, p. 45) acerca do ato de conhecer: "[...] Há uma idade em que se ensina o que se sabe; mas vem em seguida outra, em que se ensina, o que não se sabe: isso chama pesquisar". No contexto que explicitamos, a troca de saberes e de fazeres entre os sujeitos, a incerteza dos percursos investigativos, constituem chaves protagonistas para relações com o conhecimento.

\section{Considerações finais: aberturas}

Os quadros contemporâneos, caracterizados por aspectos como a aceleração dos processos de produção, transmissão, circulação e recepção de informações, combinados com o avanço e utilização das tecnologias computacionais, redimensionaram as relações e ordens em torno da leitura, da informação e conhecimento, conferindo possibilidades até então inexistentes.

Conforme Santaella $(2007$, p. 3) "[...] o que mais impressiona não é tanto a novidade do fenômeno, mas o ritmo acelerado das mudanças tecnológicas e os consequentes impactos psíquicos, culturais, científicos e educacionais que elas provocaram". Em decorrência, a "informação" adquiriu um estatuto substantivo, imperativo que a transformou não só 
em campo sociocultural autônomo, mas também em categoria definidora de uma era. (SANTAELLA, 2007). Assim, a era da informação (BURKE, 2003) tem desafiado métodos tradicionais de análise e de ação, modos de conhecer, de trabalhar, de comunicar e de educar.

O caso pontual observado na biblioteca pública inclui-se em problemática ampla que engloba tanto aspectos das dificuldades de se lidar com as informações ali armazenadas, como também de desconhecimento da própria estrutura e do valor desse dispositivo para a construção de conhecimentos e saberes específicos, fundamentais à construção do conhecimento. Se há, todavia, um salto a ser dado, uma vez que a inserção da biblioteca na vida dos estudantes - crianças e jovens, especialmente - ocorre por via das obrigações escolares, constatamos que a construção de um sentido próprio ao ato de conhecer é desprezada dentro do processo para dar lugar à eficácia dos usos do conhecimento registrado. Do mesmo modo, o lúdico sempre foi tomado como prática instrumentalizada, residual, nos processos relacionais entre sujeitos e dispositivos (tentativa de anulação da esfera do "homo ludens"), nunca observados em sua dimensão ontológica, inscrita na esfera dos desejos e manifestações humanas (tal como nos revelou a abordagem conceitual). O que é conhecer, por que conhecer, como conhecer, com que instrumentos, ou mesmo, o que é o conhecimento no contexto informacional assinalado, são aspectos que devem ser igualmente considerados.

No quadro atual contemporâneo, em síntese, tem-se um conjunto de questões situadas na base desse problema: a complexidade do quadro informacional sobre o qual não se tem, pelo menos por enquanto, ferramentas para modificá-lo; uma concepção de conhecimento como transmissão/assimilação de informações; bibliotecas e práticas culturais descoladas da ordem informacional e cultural em que se inscrevem, entre outras.

O estudo em questão assinala como estes aspectos afetam direta e concretamente as relações de crianças e jovens com o universo dos signos, sendo objetivadas em práticas cotidianas, como acontece na realização de "pesquisas escolares". Por esta razão, a redefinição de parâmetros que orientam a ideia de pesquisa em educação mostra-se cada vez mais necessária e urgente, uma vez que em nossa era da informação, a questão do acesso foi relativizada, colocando-se como nova contundente questão a problemática do saber informar-se.

Assim, concluímos que a pesquisa dialógica, negociada e espontaneamente realizada por crianças e jovens, tal como analisado a partir do quadro referido da Estação do Conhecimento apresenta-nos aspectos que podem caracterizar uma nova abordagem, não somente como forma de estimular grupos em seus processos escolares, mas, de favorecimento para a construção do valor e de vínculos com o ato de conhecer, com o conhecimento, com a cultura.

A noção de lúdico para além de sua compreensão imediata ou instrumental revela que a prática de pesquisa, nessa perspectiva, afinase, aproxima-se, articula-se à ordem do dispositivo informacional marcado 
pela dialogia, categoria essencial aos processos de construção de conhecimento e de significação. Dado que suas linguagens, configurações, dinâmicas e processos intrínsecos e extrínsecos, tendo em vista a apropriação do conhecimento, permitem a livre manifestação do brincar por seus protagonistas, seja nas atitudes participativas, críticas e criativas que ali se realizam, seja nos modos como as crianças se articulam no jogo de conhecer, o que as faz entrar em estado de fruição, excitação e integração, tal concepção revela-se promissora.

Nesses termos, a inclusão do lúdico como categoria da pesquisa, implica, todavia, um conjunto de elementos articulados que perpassam a ordem do dispositivo informacional: concepção sobre o ato de conhecer, organização do ambiente, práticas articuladas entre os diferentes mediadores, modos especiais de tratar a produção de conhecimento pelos grupos, categorias que demandam, ainda, descrição detalhada, tendo em vista possíveis contribuições a um modo diferenciado de orientar ações que permitam às crianças e jovens saber, poder e, principalmente, querer conhecer.

A apropriação cultural, como diálogo com o Conhecimento e a Cultura, conforme previsto nesta investigação, implica considerar, assim, os ambientes informacionais concretos, dispositivos nos quais o ato lúdico com os signos possa acontecer, ser inventado e reinventado, propiciando imersões efetivas dos sujeitos nas tramas sígnicas.

\section{Referências}

ARANA, M. V. de M. As reinvenções do lúdico: jogos eletrônicos, infância e cultura - um estudo exploratório. 1996. 122 f. Dissertação (Mestrado em Ciências da Comunicação) - Escola de Comunicações e Artes, Universidade de São Paulo.

BARTHES, R. Aula: aula inaugural da cadeira de semiologia literária do colégio de França, pronunciada dia 7 de janeiro de 1977. São Paulo: Cultrix, 2007. 95 p.

BENJAMIN, W. Reflexões sobre a criança, o brinquedo e a educação. 2. ed. São Paulo: Ed.34: Duas Cidades, 2009. (Coleção Espírito Crítico).

BEZERRA, M. A. da C. A pesquisa escolar nas LDBs e nos PCNs. Revista CRB-9 Digital, São Paulo, v. 1, n. 3, p. 1-18, dez. 2008. Disponível em: $<$ http://revista.crb8.org.br/index.php/crb8digital/article/view/15>. Acesso em: 24 maio 2013.

BRASIL. Leis, decretos etc. Leis de diretrizes e bases da educação nacional: Lei no. 9394, 20 de dezembro de 1996. São Paulo: SIESP, [1997?].

BROUGÈRE, G. A criança e a cultura lúdica. Revista da Faculdade de Educação, São Paulo, v. 24, n .2, p.103-116, jul./dez. 1998. Disponível em: <http://www.scielo.br/scielo.php?script=sci_arttext\&pid=S0102-

25551998000200007> Acesso em: 15 ago. 2011. 
BURKE, P. Uma história social do conhecimento: de Gutenberg a Diderot. Rio de Janeiro: Jorge Zahar Ed., 2003.

CAILLOIS, R. Os jogos e os homens: a máscara e a vertigem. Lisboa: Cotovia, 1990.

CAMPOS, F. de. A agonia lúdica: guerra, competição e fortuna nos jogos medievais. Bulletin et centre d'études médiévales d'Auxerre, n. 2, p. 1-13, 2008. Disponível em: <http://cem.revues.org/9452>. Acesso em: 25 mar. 2011.

CUNHA, N. Dicionário SESC: a linguagem da cultura. São Paulo: Edições SESC SP; Perspectiva, 2003. 779 p. (Dicionários, guias e manuais).

FERREIRA, A. B. de H. Novo dicionário Aurélio da língua portuguesa. 2. ed. Rio de Janeiro: Nova Fronteira, 1986.

HUIZINGA, J. Natureza e significado do jogo como fenômeno cultural. In: HUIZINGA, J. Homo ludens. 6. ed. São Paulo: Perspectiva, 2010. p. 3-31. (Estudos, 4).

JULIA, D. Dicionário da Filosofia. Rio de Janeiro: Larousse do Brasil, 1969. $344 \mathrm{p}$.

KISHIMOTO, T. M. Cultura lúdica como parte da cultura da infância. São Paulo: USP; LABRIMP, Laboratório de Brinquedos e Materiais Pedagógicos. Disponível

em: $<$ http://www.labrimp.fe.usp.br/index.php?action=artigo\&tipo=\&pg=1>. Acesso em: 24 jun. 2013.

LOPES. M. C. O.; TEIXEIRA, L. F. B. Ludologia e Ludicidade: texto de enquadramento. In: CONGRESSO DA SOPCOM, 4., Associação Portuguesa de Ciências da Comunicação: Repensar os Média: Novos contextos da Comunicação e da Informação, out. 2005, Aveiro. Atas... Portugal: Universidade de Aveiro, 2005. p. 437-446. Disponível em: <http://www.bocc.ubi.pt/pag/oliveira-teixeira-gt-comunicacao-ludicidade.pdf $>$. Acesso em: 22 jun. 2011.

MASTROCOLA, V. M. Ludificador: um guia de referências para o game designer brasileiro. São Paulo: independente, 2012. 104 p. Disponível em: $<$ http://www.cleberjunior.com.br/index.php/games/livros-e-e-books/31-ludificadorum-guia-de-refere-ncias-para-o-game-designer-brasileiro $>$. Acesso em: 22 jun. 2012.

MORIN, E. A cabeça bem-feita: repensar a reforma, reformar o pensamento.10.ed. Rio de Janeiro: Bertrand Brasil, 2004.

PARÂMETROS Curriculares Nacionais. Brasília: MEC: SEF, 1997.

PASSOS, M. P. de. Ludicidade e construção de saberes: mediação da informação e protagonismo em bibliotecas. Revista EDICIC, v. 1, n. 2, p. 250-264, abr./jun. 2011. Disponível em: 
<http://www.edicic.org/revista/index.php?journal=RevistaEDICIC\&page=article\&op=v iew\&path\%5B\%5D=38>. Acesso em: 20 dez. 2011.

PASSOS, M. P.; PIERUCCINI, I. Apropriação de dispositivos culturais: um estudo sobre o lúdico em bibliotecas infantis. In: CENTRO DE ESTUDOS DE TECNOLOGIAS E CIÊNCIAS DA COMUNICAÇÃO DA UNIVERSIDADE DO PORTO. Universidade de León. (Org.). VI Encontro Ibérico EDICIC: Globalização, ciência e informação: atas. 6 ed. Porto: Faculdade de Letras da Universidade do Porto; CETAC. MEDIA, 2013. p.631-642. Disponível em: $\quad<$ http://www.youblisher.com/p/745142-VI-Encontro-Iberico-EDICIC-2013Globalizacao-Ciencia-Informacao/>. Acesso em: 25 fev. 2015.

PERAYA, D. Médiation et médiatisation: le campus virtuel. Hermès, n. 25, 1999. <http://documents.irevues.inist.fr/bitstream/handle/2042/14983/HERMES 199925 153.pdf > Acesso em: 17 mar. 2013.

PERROTTI, E. Confinamento cultural, infância e leitura. São Paulo: Summus, 1990. 111 p. (Novas buscas em educação, v.38).

PERROTTI, E. A aventura de conhecer: entre a falta e o excesso de informações. Salto para o futuro, v. 28, n. 15, 3-8, set. 2008. Disponível em: <http://www.tvbrasil.org.br/fotos/salto/series/173714Aventura.pdf $>$. Acesso em: 27 jul. 2013.

PERROTTI, E.; PIERUCCINI, I. Infoeducação: saberes e fazeres da contemporaneidade. In: LARA, M. L. G, FUJINO, A. NORONHA, D. P. (org.) Informação e contemporaneidade: perspectivas. Recife: Néctar, 2007. p. 46-97. Disponível em: <http://www.pos.eca.usp.br/sites/default/files/file/ciencialnformacao/informacaoCont emporaniedade.pdf >. Acesso em: 13 fev. 2011.

PERROTTI, E.; VERDINI, A. S. Estações do conhecimento: espaços e saberes informacionais. In: ROMÃO, L. M. S. (Org.). Sentidos da biblioteca escolar. São Carlos: Alphabeto, 2008. p. 13-40.

PIERUCCINI, I. A ordem informacional dialógica: estudo sobre a busca de informação em Educação. 2004. 194 f. Tese (Doutorado) - Escola de Comunicações e Artes, Universidade de São Paulo, São Paulo. Disponível em: $\quad<$ http://www.teses.usp.br/teses/disponiveis/27/27143/tde-14032005144512/pt-br.php>. Acesso em: 20 ago. 2009.

RANCIÈRE, J. O mestre ignorante: cinco lições sobre a emancipação intelectual. 3. ed. Belo Horizonte: Autêntica, 2011.191 p.

SANTAELLA, L. Potenciais e desafios para a comunicação e inovação. Comunicação \& Inovação, v. 8, p. 2-7, 2007. Disponível em: http://seer.uscs.edu.br/index.php/revista comunicacao inovacao/article/view/667.

Acesso em: 3 mar. 2013.

SIMMEL, G. Questões fundamentais da sociologia. Rio de Janeiro: Zahar, 2006. 119 p. (Nova biblioteca de ciências sociais). 
SUSO LOPES, J. Télémaque au coeur de la "méthode" Jacotot. Documents : pour I'histoire du français langue étrangère ou second, n.30, 203. Disponível em :

$<$ https://dhfles.revues.org/1608 >. Acesso em: 12 mar. 2016. 